D, Filippatos G. Exhaled breath condensate parameters in decompensated and stable heart failure: potential new insight in the role of the alveolar capillary barrier [abstract]. Heart Failure Congress 2011, Gothenburg, Sweden.

11. Kostikas K, Papatheodorou G, Ganas K, Psathakis K, Panagou P, Loukides S. $\mathrm{pH}$ in expired breath condensate of patients with inflammatory airway diseases. Am J Respir Crit Care Med 2002;165: 1364-1370.

12. West JB, Tsukimoto K, Mathieu-Costello O, Prediletto R. Stress failure in pulmonary capillaries. J Appl Physiol (1985) 1991;70:1731-1742.

13. Dagenais A, Fréchette R, Yamagata $Y$, Yamagata T, Carmel JF, Clermont ME, Brochiero E, Massé C, Berthiaume Y. Downregulation of ENaC activity and expression by TNF-alpha in alveolar epithelial cells. Am J Physiol Lung Cell Mol Physiol 2004;286:L301-L311.

14. Faggioni R, Gatti S, Demitri MT, Delgado R, Echtenacher B, Gnocchi $P$, Heremans $H$, Ghezzi P. Role of xanthine oxidase and reactive oxygen intermediates in LPS- and TNF-induced pulmonary edema. $J$ Lab Clin Med 1994;123:394-399.

15. Birukov KG. Cyclic stretch, reactive oxygen species, and vascular remodeling. Antioxid Redox Signal 2009;11:1651-1667.

16. Janssen LJ. Isoprostanes and lung vascular pathology. Am J Respir Cell Mol Biol 2008;39:383-389.

Copyright (C) 2014 by the American Thoracic Society

\section{The Antihypertensive Effect of Positive Airway Pressure on Resistant Hypertension of Patients with Obstructive Sleep Apnea: A Randomized, Double-Blind, Clinical Trial}

\section{To the Editor:}

Resistant hypertension has been recognized as an additional risk in patients with hypertension, leading to an almost 1.5-fold increased risk of cardiovascular events among that population (1). Patients with obstructive sleep apnea (OSA) have almost five times higher risk of having resistant hypertension (2). Studies that evaluated the impact of treatment of OSA on blood pressure (BP) control among patients with resistant hypertension have some distinct methodological limitations, and none have included a sham positive airway pressure (PAP) control group (3-9).

The aim of this study was to evaluate the effect of PAP on BP measured by 24-hour ambulatory $\mathrm{BP}(\mathrm{ABP})$ monitoring of patients with true resistant hypertension. Some of the results of our trial have previously been reported in the form of an abstract (10).

All participants signed informed consent for participation. The protocol was registered in clinicaltrials.gov (NCT00929175). Patients between 30 and 70 years of age were screened in our Hypertension Outpatient Clinic (Porto Alegre, Brazil). True

Supported in part by the National Institute of Science and Technology for Health Technology Assessment-Conselho Nacional de Pesquisas, and Fundo de Incentivo a Pesquisa, Hospital de Clínicas de Porto Alegre.

Author Contributions: A.C.d.O., D. Massierer, and F.D.F. contributed to conception and design, acquisition of data, and analysis and interpretation; D. Martinez, M.G., S.C.G., and S.C.F. contributed to conception and design, and interpretation of data. A.M.S., F.G., and L.B.M. contributed to the acquisition of data; all authors critically revised the manuscript for important intellectual content, and all approved the final version to be published.

This letter has an online supplement, which is accessible from this issue's table of contents at www.atsjournals.org

Clinical trial registered with www.clinicaltrials.gov (NCT00929175). resistant hypertension was defined as an office BP of 140/90 mm $\mathrm{Hg}$ or greater in two visits, despite treatment with three or more drugs at adequate doses, including a diuretic, with adherence to treatment and without white coat phenomenon. Adherence was characterized when patients answered "no" to all questions of the Morisky-Green questionnaire (11). Office BP was measured with an aneroid sphygmonanometer (Tycos; Welch Allyn, Skaneateles Falls, NY). ABP monitoring was performed using a Spacelabs monitor (model 90207; Spacelabs, Redmond, WA). BP was measured every 20 minutes from 7:00 A.M. to 11:00 P.M. and every 30 minutes from 11:00 P.M. to 7:00 A.M. We considered an examination adequate if $80 \%$ or more of the measurements were valid. Hypertension on $\mathrm{ABP}$ monitoring was defined as a mean 24-hour BP of 130/80 mm Hg or greater.

The sleep study was performed with a type 3 portable monitoring device (Somnocheck; Weinmann GmbH, Hamburg, Germany), which was validated by our service (12). The examination was conducted at home. Recordings of artifact-free tracings shorter than 4 hours were discarded, and the examination was repeated. The apnea-hypopnea index was defined according to standard criteria (13).

Patients were randomized to active PAP or sham PAP for 8 weeks, in a 1:1 proportion in blocks of four, and stratified by systolic BP on 24-hour ABP monitoring. The active PAP (Remstar-Auto; Respironics, Murraysville, PA) was set to operate with pressures from +6 to $+12 \mathrm{~cm} \mathrm{H}_{2} \mathrm{O}$. The sham PAP used the same equipment fixed at the lowest pressure $\left(4 \mathrm{~cm} \mathrm{H}_{2} \mathrm{O}\right)$ and modified, as recommended by Farré and colleagues (14), to cause a leak that reduced the mask pressure to $1 \mathrm{~cm} \mathrm{H}_{2} \mathrm{O}$ as certified by manometer gauging. Both groups received the same instructions about the use of PAP and an operation manual with answers to the most frequent queries.

In the first 48 hours after randomization, patients were contacted to verify if the device worked, and, at the end of the first week, patients were visited at home to verify the operation and read the memory card. By the end of 8 weeks, participants underwent the second 24-hour ABP monitoring.

The sample size was calculated to detect an effect size of $10 \mathrm{~mm}$ $\mathrm{Hg}$ in 24-hour systolic ABP monitoring with a standard deviation of $12 \mathrm{~mm} \mathrm{Hg}$ and a two-sided significance level of $5 \%$.

Between February 2008 and April 2013, 47 of 538 consecutive patients screened for resistant hypertension, and with at least moderate OSA, were randomized to active PAP or sham PAP. Two patients abandoned the active PAP group, resulting in a final sample of 45 patients. The groups were roughly similar in their baseline characteristics (Table 1). Table E1 in the online supplement shows the medications and mean doses used by patients in both groups. There were no changes in the prescribed medications during the trial. Table E2 shows that the patients' adherence to the active and sham intervention was not substantially different.

Figure 1 shows that there was a significant decrease in 24-hour systolic ABP monitoring in the active versus the sham PAP group, with between-group deltas of BP variation, respectively, of $10 \mathrm{~mm} \mathrm{Hg}$ (95\% confidence interval $[\mathrm{CI}]=3.8-16.2)$ versus $0.7 \mathrm{~mm} \mathrm{Hg}(95 \% \mathrm{CI}=-5.3$ to 6.7$)(P=0.035)$. The reduction of diastolic BP did not reach formal statistical significance. Patients treated with active PAP had greater reductions in office diastolic $\mathrm{BP}$ than patients in the control group, with a between-group delta 
Table 1. Baseline Characteristics of the Study Participants according to Treatment Group

\begin{tabular}{|c|c|c|c|}
\hline Variable & Sham PAP $(n=23)$ & Active PAP $(n=24)$ & Total $(n=47)$ \\
\hline Male sex, \% & $13(57)$ & $14(58)$ & $27(57)$ \\
\hline Age, yr & $59.2 \pm 8.3$ & $59.5 \pm 7.3$ & $59.4 \pm 7.7$ \\
\hline Smokers, \% & $6(26)$ & $7(29)$ & $13(27)$ \\
\hline $\mathrm{BMI}, \mathrm{kg} / \mathrm{m}^{2}$ & $29.4 \pm 4.6$ & $30.2 \pm 4.3$ & $29.8 \pm 4.4$ \\
\hline Neck circumference, $\mathrm{cm}$ & $40 \pm 3.6$ & $40 \pm 3.4$ & $40 \pm 3.5$ \\
\hline Waist, $\mathrm{cm}$ & $102 \pm 10.4$ & $104 \pm 10.7$ & $102.9 \pm 10.5$ \\
\hline ESS $^{*}$ & $10(6-15)$ & $10(6-17)$ & $10(6-15)$ \\
\hline Drugs in the baseline & $4 \pm 1$ & $4 \pm 1$ & $4 \pm 1$ \\
\hline Office systolic BP, mm Hg & $165 \pm 17$ & $165 \pm 23$ & $165 \pm 20$ \\
\hline Office diastolic BP, mm Hg & $96 \pm 15$ & $96 \pm 17$ & $96 \pm 16$ \\
\hline Heart rate & $69 \pm 9$ & $69 \pm 9$ & $69 \pm 9$ \\
\hline $\mathrm{AHI}$, events $/ \mathrm{h}^{*}$ & $20(17-37)$ & $20.5(18-26)$ & $20(18-31)$ \\
\hline SBP-24 h, mm Hg & $146 \pm 16$ & $150 \pm 18$ & $148 \pm 17$ \\
\hline DBP-24 h, mm Hg & $88 \pm 13$ & $88 \pm 12$ & $88 \pm 13$ \\
\hline SBP-daytime, mm Hg & $148 \pm 18$ & $153 \pm 20$ & $151 \pm 19$ \\
\hline DBP_daytime, mm Hg & $90 \pm 14$ & $91 \pm 14$ & $91 \pm 14$ \\
\hline SBP_nighttime, mm Hg & $139 \pm 12$ & $140 \pm 15$ & $139 \pm 14$ \\
\hline DBP-nighttime, mm Hg & $81 \pm 10$ & $81 \pm 10$ & $81 \pm 10$ \\
\hline \multicolumn{4}{|l|}{ Comorbidities } \\
\hline Diabetes type 2, \% & $7(30.4)$ & $6(25)$ & $13(27.6)$ \\
\hline Hypothyroidism, \% & $3(13)$ & $0(0)$ & $3(6.3)$ \\
\hline Atrial fibrilation, \% & $1(4)$ & $2(8)$ & $3(6.3)$ \\
\hline Heart faillure, \% & $1(4.3)$ & $0(0)$ & $1(2.1)$ \\
\hline Ischemic cardiopathy, \% & 4 (17.3) & $3(12.5)$ & 7 (14.8) \\
\hline Stroke, \% & $2(8.6)$ & $1(4)$ & $3(6.3)$ \\
\hline
\end{tabular}

Definition of abbreviations: $\mathrm{AHI}=$ apnea-hypopnea index; $\mathrm{BMI}=$ body mass index; $\mathrm{BP}$ = blood pressure; $\mathrm{DBP}=$ diastolic BP; $\mathrm{ESS}$ = Epworth sleep sclale; $\mathrm{PAP}=$ positive airway pressure; $\mathrm{SBP}=$ systolic $\mathrm{BP}$.

Values presented are means \pm SD or percentages, unless otherwise noted.

*Median (interquartile range).

of $7.1 \mathrm{~mm} \mathrm{Hg}(95 \% \mathrm{CI}=0.5-13 ; P=0.035)$. The corresponding between-group adjusted delta of systolic BP was $5.0 \mathrm{~mm} \mathrm{Hg}$ (95\% CI $=-17$ to $7 ; P=0.431)$.

The magnitude of the BP-lowering effect, $9.3 \mathrm{~mm} \mathrm{Hg}$ for systolic BP, may lead to a substantial reduction in the incidence of cardiovascular events, such as fatal and non-fatal stroke and myocardial infarction $(15,16)$. The effect size of the main studies

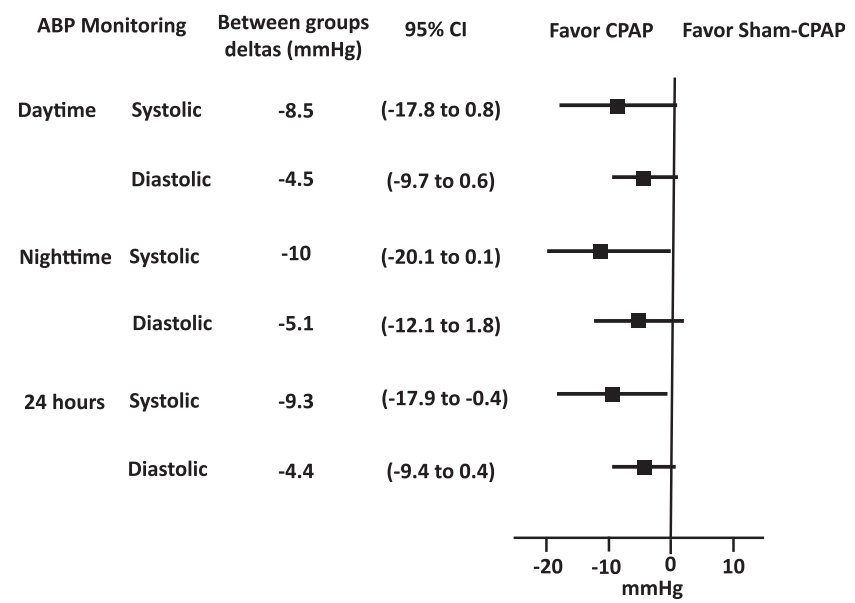

Figure 1. Deltas between blood pressure (BP) variation in the active positive airway pressure (PAP) and sham PAP groups. $\mathrm{Cl}=$ confidence interval; CPAP = continuous positive airway pressure. that evaluated the effect of PAP on BP of patients with resistant hypertension (3-7) has been shown to vary from 4.6 to $11 \mathrm{~mm}$ $\mathrm{Hg}$ in systolic BP during 24-hour, daily, or nightly periods of monitoring. Three of these studies were nonrandomized (3-5), and the main findings of the other two were restricted to subgroups $(6,7)$. The study by Pedrosa and colleagues (8) was the first to enroll patients with resistant hypertension instead of those with OSA, but did not employ a sham continuous PAP control. The Hipertensión Arterial Resistente Control con CPAP trial (HIPARCO) (9) found a somewhat lower effect of the PAP intervention, which was significant for 24-hour mean and diastolic BP. Due to its multicenter design and higher statistical power, these estimates of efficacy may be more precise. Nonetheless, there are some important differences between that trial design and ours, such as the use of sleep laboratory versus home sleep studies, the use of sham PAP in our study, and the different methods of evaluating adherence. Our patients could have more severe and true resistant hypertension, as they were older, had higher $\mathrm{ABP}$, and were using more BP-lowering drugs at baseline. In the HIPARCO trial, of 266 patients assessed for eligibility, 194 were randomized (72\%). The corresponding figures in our trial were 538 patients assessed for eligibility and 43 randomized (8.7\%). It is of note that 151 patients were excluded after dose adjustment in the run-in phase of our study.

The sample size may explain the marginal significance in our trial. We reached the originally planned sample size, but the variance of BP was higher than expected. The 2-month intervention period precludes conclusions on the persistence of the BP-lowering effect or on further BP-lowering effect if PAP 
were used for longer periods. The single-center study reduces the generalization of findings. Among the strengths of our study are the double-blinded sham PAP controlled design, the inclusion of patients with true resistant hypertension, and the measurement of BP by ABP monitoring. The screening of patients in a hypertension clinic and not in a sleep clinic increases the external validity and the applicability of our findings, as it reproduces the main clinical problem faced by clinicians and cardiologists.

In conclusion, treatment with PAP promotes a significant reduction of $\mathrm{ABP}$ in patients with true resistant hypertension and at least moderate OSA. The magnitude of the benefit should be investigated in studies with larger sample sizes and in meta-analysis of this and other randomized controlled trials.

\section{Author disclosures are available with the text of this letter at www.atsjournals.org}

Ana Claudia de Oliveira, M.D., Ph.D.

Denis Martinez, M.D., Ph.D.

Daniela Massierer, Ph.D.

Miguel Gus, M.D., Ph.D.

Sandro Cadaval Gonçalves, M.D., Ph.D.

Flávia Ghizzoni, R.N.

Ana Maria Steinhorst, M.D., M.Sc.

Leila Beltrami Moreira, M.D., Ph.D.

Sandra Costa Fuchs, M.D., Ph.D.

Flávio Danni Fuchs, M.D., Ph.D.

Hospital de Clínicas de Porto Alegre, Universidade Federal do Rio Grande do Sul Porto Alegre, Brazil

\section{References}

1. Daugherty SL, Powers JD, Magid DJ, Tavel HM, Masoudi FA, Margolis KL, O'Connor PJ, Selby JV, Ho PM. Incidence and prognosis of resistant hypertension in hypertensive patients. Circulation 2012;125: 1635-1642.

2. Gonçalves SC, Martinez D, Gus M, de Abreu-Silva EO, Bertoluci C, Dutra I, Branchi T, Moreira LB, Fuchs SC, de Oliveira AC, et al. Obstructive sleep apnea and resistant hypertension: a case-control study. Chest 2007;132:1858-1862.

3. Logan AG, Tkacova R, Perlikowski SM, Leung RS, Tisler A, Floras JS, Bradley TD. Refractory hypertension and sleep apnoea: effect of CPAP on blood pressure and baroreflex. Eur Respir J 2003;21:241-247.

4. Martínez-García MA, Gómez-Aldaraví R, Soler-Cataluña J-J, Martínez TG, Bernácer-Alpera B, Román-Sánchez P. Positive effect of CPAP treatment on the control of difficult-to-treat hypertension. Eur Respir $J$ 2007;29:951-957.

5. Dernaika TA, Kinasewitz GT, Tawk MM. Effects of nocturnal continuous positive airway pressure therapy in patients with resistant hypertension and obstructive sleep apnea. J Clin Sleep Med 2009;5:103-107.

6. Lozano L, Tovar JL, Sampol G, Romero O, Jurado MJ, Segarra A, Espinel E, Ríos J, Untoria MD, Lloberes P. Continuous positive airway pressure treatment in sleep apnea patients with resistant hypertension: a randomized, controlled trial. J Hypertens 2010;28:2161-2168.

7. Litvin AY, Sukmarova ZN, Elfimova EM, Aksenova AV, Galitsin PV, Rogoza AN, Chazova IE. Effects of CPAP on "vascular" risk factors in patients with obstructive sleep apnea and arterial hypertension. Vasc Health Risk Manag 2013;9:229-235.

8. Pedrosa RP, Drager LF, de Paula LKG, Amaro ACS, Bortolotto LA, Lorenzi-Filho G. Effects of OSA treatment on BP in patients with resistant hypertension: a randomized trial. Chest 2013;144: 1487-1494.

9. Martínez-García MA, Capote F, Campos-Rodríguez F, Lloberes P, Díaz de Atauri MJ, Somoza M, Masa JF, González M, Sacristán L, Barbé F, et al.; Spanish Sleep Network. Effect of CPAP on blood pressure in patients with obstructive sleep apnea and resistant hypertension: the HIPARCO randomized clinical trial. JAMA 2013;310:2407-2415.
10. Oliveira AC, Massierer D, Martinez D, Fuchs FD. Blood pressure-lowering effect of CPAP in patients with resistant hypertension and obstructive sleep apnea: preliminary results of a randomized controlled trial [abstract]. Arq Bras Cardiol 2013;101 (2 Suppl 1):8.

11. Morisky DE, Green LW, Levine DM. Concurrent and predictive validity of a self-reported measure of medication adherence. Med Care 1986;24:67-74.

12. Tonelli de Oliveira AC, Martinez D, Vasconcelos LF, Gonçalves SC, Lenz MC, Fuchs SC, Gus M, Abreu-Silva EO, Moreira LB, Fuchs FD. Diagnosis of obstructive sleep apnea syndrome and its outcomes with home portable monitoring. Chest 2009;135:330-336.

13. Sleep-related breathing disorders in adults: recommendations for syndrome definition and measurement techniques in clinical research. The report of an American Academy of Sleep Medicine Task Force. Sleep 1999;22:667-689.

14. Farré R, Hernández L, Montserrat JM, Rotger M, Ballester E, Navajas D. Sham continuous positive airway pressure for placebo-controlled studies in sleep apnoea. Lancet 1999;353:1154.

15. Law MR, Morris JK, Wald NJ. Use of blood pressure lowering drugs in the prevention of cardiovascular disease: meta-analysis of 147 randomised trials in the context of expectations from prospective epidemiological studies. BMJ 2009;338:b1665.

16. Fuchs FD, Fuchs SC, Moreira LB, Gus M. Proof of concept in cardiovascular risk: the paradoxical findings in blood pressure and lipid abnormalities. Vasc Health Risk Manag 2012;8:437-442.

Copyright (C) 2014 by the American Thoracic Society

\section{Does Inspiratory Muscle Dysfunction Predict Readmission after Intensive Care Unit Discharge?}

\section{To the Editor:}

Dysfunction of peripheral and respiratory muscles acquired in the intensive care unit (ICU) is associated with poor outcome, including delayed weaning from mechanical ventilation (1). Controlled mechanical ventilation can result in diaphragm atrophy (2), and critical illness polyneuromyopathy can also involve respiratory muscles (1). Diaphragm dysfunction may exist upon ICU admission and is associated with ICU and hospital mortality (3). However, the prevalence and impact of inspiratory muscle dysfunction in patients who have survived an episode of acute hypercapnic respiratory failure (AHRF) in the ICU have not been reported to date.

In the present study, we performed a prospective follow-up of all patients recovering from an episode of AHRF after ICU discharge and measured sniff nasal inspiratory pressure (Pnas) at Day 7 after ICU discharge. We recorded readmissions for respiratory causes to the general wards and to the ICU during a 6-week period after ICU discharge. Sniff Pnas was performed according to the American Thoracic Society/European Respiratory Society recommendations (4). The 5th percentile Pnas value of a healthy population of the same age and gender was used as a cut-off value for inspiratory

\section{Supported by the Pulmonary League of Geneva.}

Author Contributions: D.A., J.-C.R., J.-P.J., and L.B. designed the study; D.A. and J.-C.R. coordinated the study; D.A. was responsible for patient screening, enrollment, and follow-up; D.A. and E.D.-L. performed statistical analysis; and D.A., J.-P.J., and L.B. analyzed the data and wrote the manuscript. All authors contributed to interpretation of the data and provided comments on the report at various stage of development. 